\title{
Burocracia profissional e a livre nomeação para cargos de confiança no Brasil e nos EUA
}

Luir Alberto dos Santos

\section{Introdução}

As questões relativas à utilização de cargos de livre nomeação e exoneração, convivendo em paralelo com a estrutura de cargos de provimento efetivo (carreiras) na estrutura burocrática, para assegurar o comando político e administrativo na máquina pública, têm sido objeto, tanto no Brasil quanto nos Estados Unidos da América (EUA), de diversos estudos ao longo dos anos. Em ambos os contextos de democracias presidencialistas e governos federativos, o uso desses cargos tem sido associado ora à patronagem, ora à necessidade de conferir capacidade de comando aos governos eleitos. Mas, em diferentes medidas, o que se constata é o excesso desse tipo de cargo e a assimetria de estruturas burocráticas profissionalizadas que possam atender a contento às necessidades dos governos.

A existência de cargos de confiança é inerente ao regime democrático, em que aos dirigentes eleitos confere-se certo grau de liberdade para compor as estruturas de comando. Tanto a literatura mais recente quanto as observações factuais, no 
entanto, demonstram que há necessidade de definição dos casos em que tais cargos devem ser livremente providos, para se evitar que a nomeação política se torne regra. Embora essa seja uma necessidade para o governo imprimir sua marca à gestão e permitir que o comando político exerça controles verticais mínimos sobre a burocracia de carreira, trata-se de um mecanismo que, empregado sem critério, dá margens a sérias distorções.

Este trabalho debate a situação em ambos os países, com base em alguns dados esclarecedores obtidos pela comparação entre as estruturas de cargos comissionados, no Brasil e EUA, no nível do governo federal, relativos à quantidade, tipos e emprego dos cargos em comissão. Procura, também, apontar cenários que indiquem que uma estrutura menos vulnerável às injunções da política clientelista possa melhor atender aos princípios da eficiência e da transparência, sem gerar, por outro lado, uma burocracia avessa ao controle político dos governos legitimamente eleitos.

\section{Cargos em comissão e controle burocrático no Governo dos EUA}

O nível de politização dos cargos executivos - caracterizado pela nomeação de pessoas que não integram os quadros permanentes para chefiar os servidores de carreira ou pela nomeação dessas pessoas para ocupar cargos burocráticos importantes, anteriormente exercidos por servidores de carreira (LEWIS, 2005) - é, nos EUA, um problema complexo, que comporta diversas abordagens. Não se pode fazer uma leitura maniqueísta do quadro existente, havendo razões relevantes em favor tanto dos que defendem a redução do número de cargos de livre nomeação (Ballenstedt, 2007; Maranto, 2001) quanto sua ampliação, e tampouco existe, apesar de se tratar de um debate antigo, consenso sobre qual a melhor alternativa para assegurar uma boa gestão (LEWIs, 2007, p. 1.074).

A politização das agências governamentais segue um padrão que, segundo Lewis $(2005 ; 2007)$, é o de buscar conceder ao presidente os meios para exercer controle sobre a burocracia e fazer com que sua ação se dê conforme as suas diretrizes, ou contornar situações em que a burocracia das agências tem preferências distintas das suas.

No que se refere aos cargos cuja investidura depende de critérios políticos political appointments-, sua existência é bastante reduzida, ainda que, em comparação com outros países desenvolvidos, seja tida como elevada. Seu uso, todavia, não difere substancialmente do que ocorre em países onde a gestão é mais "politizada", como demonstra Golden (2000, p.157), a partir do exemplo do uso desses cargos pelo Governo Reagan para "contornar" as resistências dos executivos de carreira na implementação das decisões políticas presidenciais.

Segundo dados do Office of Personnel Management, em 2001, o presidente da República podia indicar livremente, por critérios políticos, 2.073 cargos. Além desses, havia cerca de 1.000 cargos em agências reguladoras, em que ainda hoje prevalece o critério, fixado em lei, de que cabe a cada um dos dois partidos (Democrático e Republicano) indicar, alternadamente (bipartisan basis), os membros das comissões independentes de regulação de setores econômicos.

A cada quatro anos, após a eleição presidencial, é publicada alternadamente, pela House of Representatives e pelo Senado, a relação de cargos que podem ser 
preenchidos por critérios políticos. A publicação, denominada United States Government Policy and Supporting Positions, popularmente conhecida por Plum Book, inclui dados detalhados sobre os cargos, nos poderes Executivo e Legislativo, que exercem funções de liderança ou suporte aos cargos políticos e que podem ser preenchidos por livre nomeação. O critério geral é que tais cargos envolvem posições de defesa das políticas públicas e programas governamentais e maior nível de proximidade e confidencialidade no seu relacionamento com os agentes ou dirigentes políticos, como o presidente e o vicepresidente da República, seus Chiefs of Staff e os chefes de departamento.

A edição desse relatório de novembro de 2004, publicada pelo Committee on Government Reform da U.S. House of Representatives, apontou a existência de cerca de 4.500 cargos de livre nomeação, incluídos os cargos das comissões reguladoras independentes, das agências executivas do governo federal, das secretarias (ministérios), de órgãos da Presidência, como o Office of Personnel Management e Office of Management and Budget, e de órgãos ligados ao Poder Legislativo, como o Government Accountability Office e a Library of Congress. A distribuição dos cargos, por tipo, está descrita na Tabela 1.
Assim, segundo essa fonte oficial, o total de postos providos por critérios políticos no governo federal dos EUA atingia, em 2004, efetivamente, 4.496 cargos; uma vez que, entre os 4.555 cargos classificados como GEN, que diz respeito aos cargos do Senior Executive Service que não integram a carreira, somente os 701, classificados como $\mathrm{NA}$, poderiam, efetivamente, ser providos simultaneamente por critérios políticos.

Como exemplos, na Federal Communications Commission, uma das mais importantes comissões reguladoras independentes, somente 18 cargos, inclusive os de mais alto nível, podem ser providos por cidadãos que não sejam servidores efetivos. $\mathrm{Na}$ Social Security Administration, equivalente norte-americano do Instituto Nacional do Seguro Social, e que tem um total de 64.500 funcionários, somente 44 cargos podem ser providos livremente pelo governo. Por outro lado, o Executive Office of the President, órgão de natureza claramente política integrado por diversos órgãos da Presidência da República, dispõe de número comparativamente elevado de cargos que podem ser preenchidos livremente: $115 \mathrm{PA}$, 23 PAS, 21 NA, 34 XS e 49 SC. Do total de 242 cargos, somente 23 são sujeitos à

Tabela 1: Cargos de Livre Nomeação no Governo dos EUA - por espécie - 2004

\begin{tabular}{l|c|c|c|c|c|c|c}
\hline Tipo & PAS & PA & GEN & NA & LA & SC & XS \\
\hline Quantidade & 1.137 & 320 & 4.555 & 701 & 118 & 1.596 & 624 \\
\hline
\end{tabular}

Fonte: Committee on Government Reform U.S. House of Representatives. Policy and Supporting Positions. Novembro 2004.

Notas: PAS = Cargos indicados pelo Presidente, mas sujeitos à aprovação do Senado; PA = Cargos indicados pelo Presidente, sem aprovação do Senado; GEN = Posições Gerais do Senior Executive Service, passíveis de livre nomeação e exoneração (desde que satisfeitos requisitos de qualificação); NA = Postos totais do Senior Executive Service efetivamente ocupados por pessoas de fora da carreira, em virtude do limite de 10\%; $\mathrm{LA}=$ Postos do Senior Executive Service ocupados em caráter emergencial ou temporário; $\mathrm{SC}=$ Postos de confiança política, definidos na Tabela C (Schedule C), excetuados do sistema do mérito em razão de suas atribuições de formulação de políticas; XS = Postos excepcionalmente sujeitos a indicação política. 
confirmação prévia pelo Senado. O Department of Labor, por sua vez, pode nomear 148 pessoas por critérios políticos. Já no Internal Revenue Service, só é permitida a nomeação de dois dirigentes por critérios políticos - e ambos sujeitos à aprovação do Senado.

Os dados do governo federal dos EUA apontam que, do total de cargos de livre nomeação ou cuja nomeação se dá por critérios políticos relacionados pelo Plum Book em 2004, 1.137 dependem da aprovação do Senado - 54\% estão localizados em apenas 10 principais órgãos e agências, e os demais $46 \%$ estão distribuídos por outras 109 unidades, incluindose agências e departamentos do governo e do Legislativo. Além disso, apenas 33 órgãos dispõem de mais de 25 cargos de livre provimento.

Esses números são indicativo da pouca liberdade dos dirigentes políticos para lotear a máquina pública ou adotar critérios de preferências político-partidárias para ocupar postos gerenciais. No entanto, percebe-se ainda a persistência de práticas associadas ao spoils system, assim como a disputa entre os ocupantes de cargos políticos e os burocratas de carreira. Segundo Golden, o uso de nomeações de cargos políticos, por meio da Schedule $C$, e dos cargos de livre provimento do SES constitui importante instrumento para que o presidente da República faça nomeações estratégicas em todos os níveis da organização, e não apenas nos níveis superiores, escolhidos de acordo com critérios ideológicos ou de confiança. Com isso, poderia exercer melhor monitoramento das atividades dos servidores de carreira, além de assegurar a lealdade dos responsáveis por funções de linha (GOLDEN, 2000, p. 6-7).

Historicamente, percebe-se que o número de cargos de indicação política aumentou expressivamente a partir da década de 1930 e a taxas muito superiores à do quantitativo geral da força de trabalho no serviço público. Se, em 1933, eram computados cerca de 200 cargos políticos, em 1989, esses aproximam-se de 3 mil. Já o número de cargos políticos que dependem da aprovação do Senado aumentou, de 1933 até 1965 , de 73 para 152, chegando a 573 em 1989 (LEWIS, 2005). A evolução do percentual de cargos políticos em relação ao total de servidores federais, entre 1960 e 2004, é a que consta do Gráfico 1.

Desde então, esses números continuam aumentando, tanto em governos democratas quanto republicanos, e parte da elevação se deve à facilidade com que o presidente pode criar novos cargos na Schedule $C$, a serem providos livremente. $\mathrm{E}$, conforme referido, também os cargos cuja investidura é condicionada à aprovação do Senado e que dependem de lei para sua criação têm experimentado crescimento expressivo.

Nos cinco primeiros anos do Governo George W. Bush (2001-2005), 307 novos cargos de nomeação política foram criados, aumentando o número total em 12\%. O número de cargos da Schedule $C$, preenchidos sem a aprovação do Congresso, aumentou em 33\% em relação ao total existente em 2000. Considerando-se que, durante o Governo Clinton, o número total de cargos de livre nomeação sofreu queda de $17 \%$, com uma redução de $27 \%$ nos cargos da Schedule $C$, a reversão dessa tendência tem gerado polêmicas e sofrido a crítica da minoria democrata na House of Representatives, manifestada no Relatório do Comitê de Reforma do Governo divulgado em maio de 2006, conforme relatório de 2006 do Committee on Government Reform da U.S. House of Representatives. 


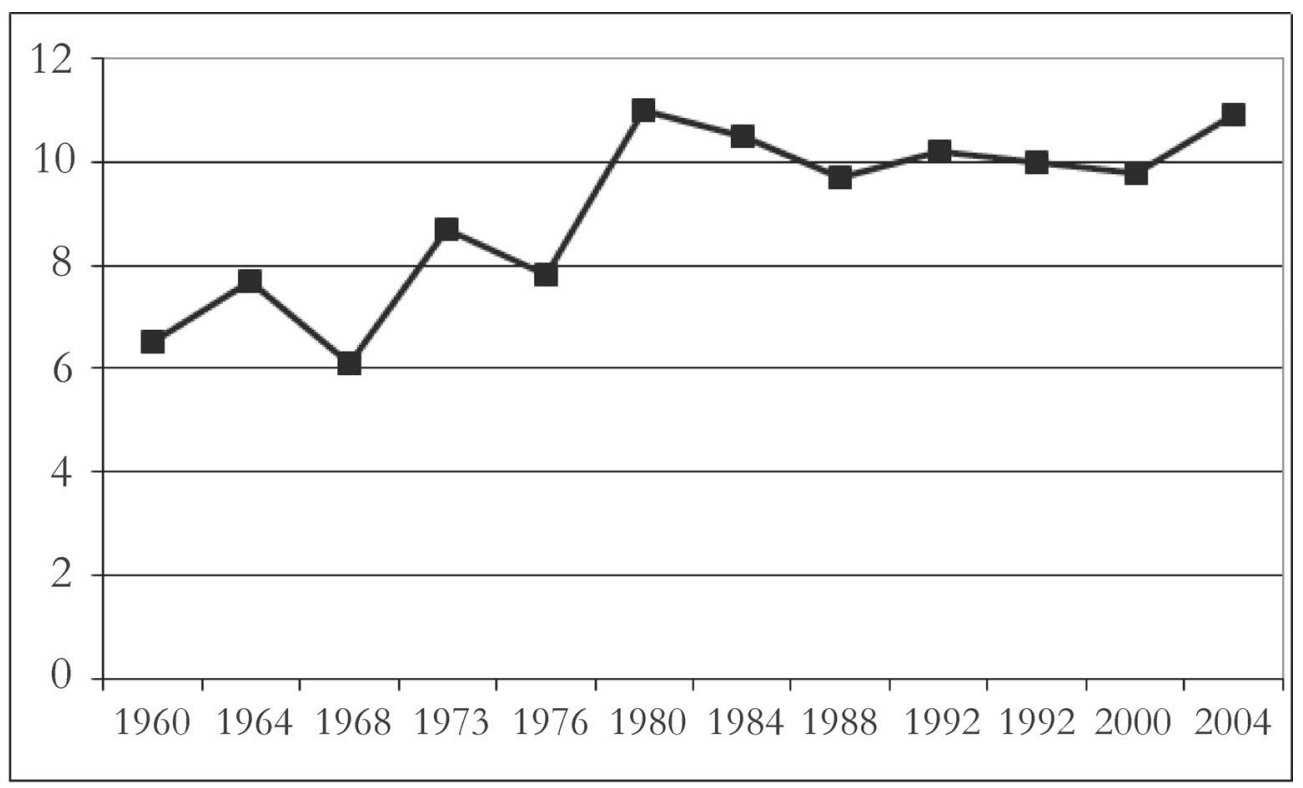

Fonte: Lewis, 2005, com dados do Plum Book 1960-2004.

\section{Gráfico 1: Cargos providos por critérios políticos em $\%$ do total de servidores federais - EUA, 1960-2004}

Apesar da reprimenda, o nível de apoio do Legislativo à politização, segundo Lewis (2005), varia conforme o contexto, e não necessariamente a politização será apoiada como regra, uma vez que, se o objetivo é tornar a administração mais ajustada às visões do presidente, isso não significa que haverá afinidade com a posição dos congressistas sobre as políticas a serem implementadas. Segundo Lewis, o apoio dos congressistas às nomeações políticas dependerá de quão similares forem as suas preferências e as do presidente em relação às políticas públicas - quanto maior for a convergência, mais o Congresso apoiará a politização. Em consequência, aponta uma divisão entre os membros do Congresso quanto às vantagens da politização dos cargos de direção.

A discussão sobre o conflito entre "competência neutra" e "competência responsiva" remonta, segundo Krause e outros (2006, p. 771), a estudos de Heclo (1975) e Kaufman (1956), os quais argumentaram que os presidentes, nos EUA, deveriam buscar competência neutra, enfatizando a contratação de profissionais de carreira em lugar de cargos políticos, valorizando a expertise a fim de obter os melhores resultados. Segundo essa perspectiva, a seleção por critérios políticos teria efeitos opostos, e os profissionais recrutados por esse meio tenderiam a ter sua conduta mais influenciada pelas instituições responsáveis pela sua indicação, além do sistema de recrutamento exibir maior turnover e produzir sinais mais voláteis a respeito das políticas e objetivos das agências. Moe (1985 apud Krause et al, 2006, p. 771) considera que as deficiências dos burocratas de carreira em relação à compreensão e lealdade obrigavam os presidentes a manipular as regras do serviço civil e a propor reorganizações e mudanças 
legais para ampliar o número e a alocação de posições administrativas a serem providas por critério político. Além disso, conforme Bok (2003, apud KRAUSE et al, idem) os political appointees teriam maior capacidade de combater a inércia, assegurar $o$ influxo de novas ideias e manter o governo em contato com uma variedade de grupos de interesse e constituencies. Seriam, portanto, mais capazes de assegurar uma "competência responsiva".

Segundo Lewis (2005), existe nessa questão um paradoxo, também apontado por Rourke (1976): se os cargos políticos fazem com que o governo seja responsivo aos oficiais eleitos ${ }^{1}$, um número excessivo desses cargos faz com que o governo tenha sua competência reduzida e deixe, assim, de ser responsivo à sociedade. A eficiência depende, em parte, de um corpo profissional e contínuo, imune às interferências e às influências políticas diretas. Assim, o caráter antidemocrático dessa burocracia ajuda o governo a ser responsivo aos cidadãos.

Sob o prisma da vinculação entre profissionalização, politização e eficiência administrativa, Lewis $(2005 ; 2007)$ demonstra que as agências governamentais em que há maior número de dirigentes nomeados politicamente são as que demonstram os piores indicadores de eficiência. Embora outros fatores possam interferir no desempenho administrativo, como a complexidade das tarefas, orçamento e cultura organizacional, esse indicador, segundo Krause e outros (2006, p. 772), é fator relevante para explicar parte do desempenho das instituições, embora frequentemente desconsiderado. Em conclusão, Lewis (2005) afirma que "a politização resulta em redução da competência das agências", afetando sua capacidade e eficiência, reduzindo o moral $\mathrm{da}$ organização, sua expertise e capital humano. Além disso, programas administrados por dirigentes indicados politicamente têm alcançado, sistematicamente, resultados inferiores aos de programas administrados por executivos de carreira (LEWIS, 2007, p. 1.074). Krause e outros (2006, p. 772), todavia, consideram que recentes evidências empíricas mostram que as diferenças de desempenho vêm-se reduzindo, como resultado da elevação do nível de qualificação dos political appointees, maior experiência pregressa em cargos governamentais e maior permanência nos cargos. Lewis (2007) confirma a avaliação quanto à qualificação dos cargos políticos, mas não a corrobora no que se refere aos resultados alcançados na gestão de programas.

Os dados apurados por Lewis (2007, p. 1.086) levam à conclusão de que a redução do número de cargos políticos, ou sua estabilização, pode ser um meio para melhorar a capacidade de gestão. A pesquisa por ele realizada indicou que a ampliação do "controle democrático" da burocracia, mediante o uso de cargos providos por critérios políticos, pode ser prejudicial à competência, enquanto um corpo profissional de executivos de carreira, competentes em sua tarefa, pode contribuir para a efetividade do governo. Criar esse corpo profissional, porém, traz o desafio de tornar o governo democrático, tanto estabelecendo uma gestão competente quanto controlando a autonomia que decorre dessa competência. Nos EUA, a questão torna-se ainda mais evidente, tendo em vista a cultura política amplamente refratária à ideia da criação de uma "classe aristocrática" (no caso, a burocracia) não responsiva.

Sob o prisma dessa experiência, portanto, sobreleva-se o papel dos cargos em comissão como forma de contrabalançar o poder da burocracia e assegurar 
o seu controle político, mais do que servir ao propósito de permitir a apropriação fisiológica dos meios administrativos. Apesar das diferenciações que existem entre as respectivas burocracias no que se refere à sua composição, histórico e a dimensão de sua influência sobre o processo decisório governamental, este é, sem dúvida, o principal aspecto distintivo em relação ao caso brasileiro, como se verá a seguir.

A fragilidade da burocracia no Brasil: executivos públicos versus o (ab)uso dos cargos de confiança

A organização da burocracia no Brasil, desde seus primórdios, foi afetada pelo uso corriqueiro das contratações fora do sistema do mérito para posições "temporárias" ou precárias, da burla ao concurso público como forma de ingresso nos cargos e empregos permanentes. Como contraponto, deu-se, historicamente, o uso das formas de livre provimento para o exercício de cargos "de confiança", voltados a permitir que, a cada momento, os dirigentes dos órgãos e entidades públicas pudessem ser selecionados segundo os critérios de confiança e conveniência dos detentores do poder político.

Durante todo o processo de constituição dos quadros permanentes da burocracia federal, abundaram no Brasil os cargos em comissão de livre nomeação e exoneração, cujo provimento jamais foi vinculado de maneira geral à posse de cargos efetivos. Apesar de tentativas cosméticas de "enxugamento", os cargos foram sempre numerosos e se tornaram moeda de troca na busca de apoio político por parte do governo, quando não se constituíam em mera apropriação clientelista, fisiológica ou nepotista de postos de trabalho, cujo acesso se dá sem concurso público. As tentativas de fixar regras limitadoras do seu exercício, por meio de sua vinculação a carreiras ou ao sistema do mérito, foram ora tímidas, ora inefetivas, pela própria ausência de servidores com o perfil necessário para poderem prover a administração de quadros capazes de garantir a continuidade administrativa e refrear a tendência ao clientelismo. Conforme salienta Baquero:

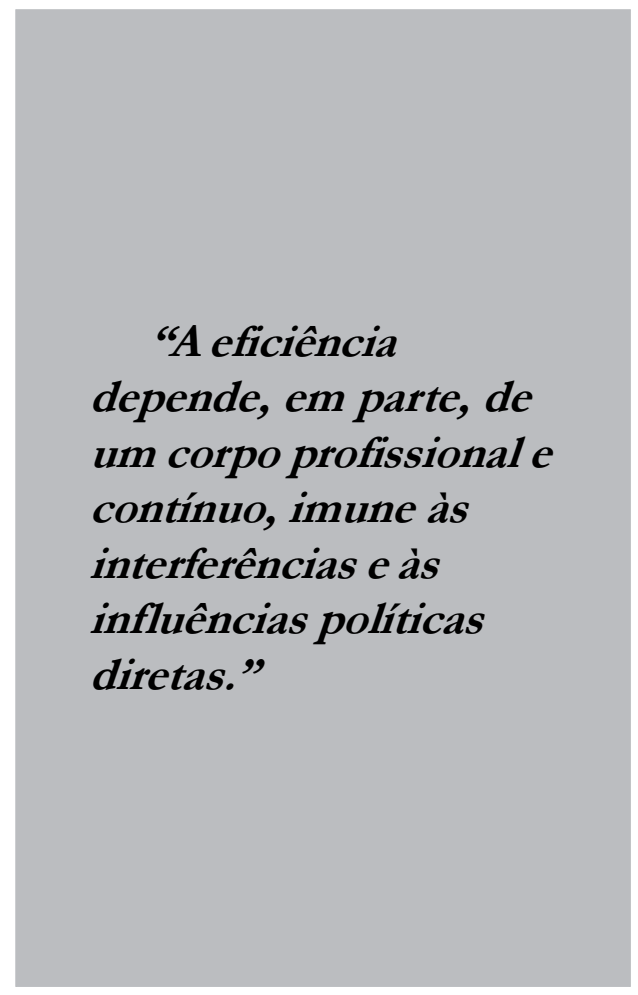

Contemporaneamente, tanto o clientelismo quanto o nepotismo são atribuídos ao número excessivo de cargos de confiança que favorece as práticas ilícitas (AYLLón e GUERrERO, 2005). Para esses autores, a presença de funcionários apadrinhados por partidos governamentais nas empresas estatais é uma prática habitual no Brasil 
e é parte do sistema exigido pela voracidade dos seus líderes que financiam, assim, suas atividades políticas.

$\mathrm{Na}$ virada do milênio, os governos brasileiros continuam a criar cargos de confiança de forma nefasta para os interesses do país. Segundo Abramo, da Transparência Brasil, 'os partidos querem cargos de direção nas estatais e na administração direta porque ali podem conduzir negócios, ou, melhor dizendo, negociatas' (ABRAMo, 2007, p. 15). As instituições identificadas como as mais afetadas pela corrupção na pesquisa do Inea (2006) foram o Congresso, os partidos e o governo central (BAQUERO, 2007, p. 235).

No entanto, mesmo enfrentando resistências culturais e políticas, o ordenamento jurídico nacional tem avançado na direção do sistema de mérito, inclusive na esfera constitucional. Até a Emenda Constitucional no $19 / 98$, as únicas regras editadas no âmbito federal para limitar o grau de politização das chefias haviam sido o art. 10 do Decreto-Lei n ${ }^{\circ}$ 1.660, de janeiro de 1979 (que determinou que a designação para os cargos classificados abaixo do quinto nível hierárquico recairia, em 50\% dos casos, em servidor ocupante de cargo permanente), e o art. $11 \mathrm{da}$ Lei $\mathrm{n}^{\circ}$ 8.460, de setembro de 1992 (que elevou essa regra até o quarto nível hierárquico - DAS 3) ${ }^{2}$. Embora a Lei $\mathrm{n}^{-}$ 8.911, de julho de 1994, tenha determinado que a totalidade dos cargos de chefia inferiores ao quarto nível hierárquico (DAS 4) e $60 \%$ dos cargos de assessoramento de cada órgão somente poderiam ser preenchidos por servidor ocupante de cargo efetivo, tal regra não resistiu às pressões políticas, tendo sido inicialmente suspensa e finalmente revogada a partir de janeiro de 1995, sem sequer ter entrado em vigor.

Em termos gerais, a Carta de 1988 incorporou dois pressupostos básicos em relação aos cargos comissionados. O primeiro diz respeito à inexigibilidade de concurso público para acesso a esses cargos (art. 37, II da CF); o segundo, à preferência, no seu provimento, para servidores ocupantes de cargo de carreira técnica ou profissional (art. 37, $\mathrm{V}$ da CF). A nova redação dada ao art. $37, \mathrm{~V}$ da Constituição pela Emenda Constitucional no 19, de 1998, aperfeiçoou o comando, assegurando exclusividade para o servidor de carreira no provimento de funções de confiança, ao mesmo tempo em que mantém a necessidade de lei para definir casos, condições e percentuais mínimos em que os cargos em comissão, destinados apenas às atribuições de direção, chefia e assessoramento, deverão ser preenchidos por servidores de carreira. Em tese, o comando seria capaz de permitir a redução das hipóteses de comissionamento - que, segundo o mesmo dispositivo, somente poderiam ser empregadas para atribuições de direção, chefia ou assessoramento -, mas, na prática, permanece sem aplicação, pois a lei prevista não foi editada e tampouco se redefiniram as estruturas de comissionamento a fim de reduzir as hipóteses de livre provimento. Tal fato é antitético à idéia de dotar o Estado de maior capacidade de governança, uma vez que, levando-se em consideração o caráter patrimonialista que permeia o contexto de utilização dos cargos públicos, seria de se esperar que a redução do espaço para as nomeações políticas ou para a rotatividade das chefias tivesse o aspecto moralizador de retirar de circulação a "moeda de troca" associada à corrupção e à subversão do sistema do mérito, além de contribuir para 
o aumento da eficácia e da eficiência da ação do governo.

O uso pouco criterioso dos cargos em comissão e seu uso para atender a pressões político-partidárias tem sido prática corriqueira na administração pública brasileira ${ }^{3}$. Contudo, nos últimos dez anos, tem-se intensificado o questionamento de seu uso clientelista e nepótico, notadamente no caso dos cargos em comissão, ou como forma de assegurar o apoio dos partidos no Congresso. Apesar da redução do uso de cargos, em decorrência do processo de privatização de empresas estatais no período, existem, ainda, milhares de cargos qualificados de livre nomeação, disputados avidamente pelos "afilhados", parentes ou cabos eleitorais de parlamentares, nas mais diversas áreas de governo.

Mesmo o governo do presidente Luiz Inácio Lula da Silva, cujo partido historicamente ergueu a bandeira da luta contra a corrupção e o nepotismo, tem sido acusado de promover o mau uso dos cargos em comissão. Os partidos de oposição (DEM e PSDB) têm centrado o foco de suas críticas no que seria o "aparelhamento partidário" do governo, pelo uso excessivo de nomeações políticas para cargos de confiança. Outras denúncias de pequeno porte continuaram a aparecer, envolvendo a utilização de cargos públicos para acomodação de candidatos não eleitos. Não tem passado sem atenção, também, o fato de que, para manter sua base de sustentação no Congresso Nacional, o governo precisa atender às demandas por loteamento de organizações - e, por conseguinte, de cargos - e pela liberação de recursos orçamentários oriundos de emendas parlamentares.

Há, nas práticas administrativas assim determinadas, uma clara distorção da forma como são considerados os cargos públicos: prevalece uma visão patrimonialista, personalista, como se o cargo fosse propriedade de quem dele dispõe para livre nomeação e que tal investidura não devesse observar os princípios da impessoalidade e moralidade, ou mesmo existisse à revelia do interesse público, mas para satisfação do interesse pessoal do agente político.

A sensação de que o país não se empenha em reduzir as práticas fraudulentas é também compartilhada por muitos formadores de opinião internos. Cresce, nos meios de comunicação de modo geral, o consenso de que a rotineira ocorrência de denúncias de casos de corrupção - muitos decorrentes de empreguismo, loteamento de cargos em organizações públicas e baixa profissionalização dos quadros dirigentes afeta não apenas o governo, mas enfraquece o Estado de Direito, implicando o aumento generalizado da desconfiança da população em relação à classe política e às instituições.

Sob essa perspectiva, tem-se mostrado recomendável adotar medidas restritivas da apropriação dos cargos públicos e, especialmente, dos cargos em comissão. Para tanto, o estabelecimento de um nível hierárquico a partir do qual os cargos de direção nos órgãos e entidades só podem ser providos exclusivamente por servidores do quadro efetivo das instituições e até mesmo em escalões superiores, quando justificável pelo nível de especialização envolvido, tem sido considerado medida eficaz e necessária.

A alteração promovida ao inciso $\mathrm{V}$ do art. 37 da CF pela Emenda Constitucional no 19/98 foi, sem dúvida, um passo importante no sentido de reduzir o uso discricionário dos cargos em comissão, embora timidamente. A nova redação dada ao dispositivo veio expressamente proibir a criação e uso, ainda que autorizados 
em lei, de cargos comissionados para finalidades estranhas às expressamente previstas, o que desde logo impede, por exemplo, o uso dos cargos para burlar o concurso público, mediante a nomeação precária para cargos cujas tarefas sejam típicas de cargos efetivos ou empregos permanentes.

Apesar da aridez do terreno para semear iniciativas de profissionalização da gestão pública, ao oferecer critérios mais objetivos e meritocráticos para ocupação de cargos de dirigentes e assessores na administração pública federal, ainda é possível localizar iniciativas nesse sentido e acompanhar seus percalços.

$\mathrm{Na}$ Fundação Nacional de Saúde (Funasa), o Decreto no 3.450, de 9 de maio de 2000, instituiu regra que limitava a ocupação de cargos em comissão por não servidores nas suas unidades descentralizadas, aplicável, porém, somente às nomeações futuras. Tais normas, entretanto, foram consideradas excessivamente restritivas, uma vez que estabeleciam exigências intransponíveis para a maior parte dos servidores, o que levou à edição do Decreto $\mathrm{n}^{\mathrm{o}}$ 4.615, de 18 de março de 2003, estabelecendo que os ocupantes dos cargos em comissão das unidades descentralizadas da Funasa seriam escolhidos, preferencialmente, entre os servidores ocupantes de cargo efetivo na administração pública federal. Assim, o que antes era obrigatoriedade passou a ser meramente uma preferência, condicionando-se regra mais restritiva à regulamentação do art. $37, \mathrm{~V}$ da $\mathrm{CF}$.

No Instituto Nacional do Seguro Social (INSS), o Anexo I do Decreto $\mathrm{n}^{\mathrm{o}}$ 569, de 16 de junho de 1992, estabeleceu, como regra, o provimento privativo, por servidores efetivos da autarquia, dos cargos comissionados até o nível DAS 3, e que a nomeação para o exercício dos cargos em comissão de superintendente estadual, dos níveis DAS 3 e 4, deveria recair, exclusivamente, em ocupantes de cargos efetivos da administração pública federal direta, autárquica e fundacional. A regra foi alterada pelo Decreto $\mathrm{n}^{\mathrm{o}}$ 3.081, de 10 de junho de 1999, cujo Anexo I estabeleceu, ainda, que os cargos de gerente-executivo, de nível DAS 4, seriam escolhidos em processo seletivo interno, do qual somente poderiam participar servidores do INSS. Já os cargos de menor nível hierárquico seriam providos por livre escolha do dirigente, mas entre servidores da autarquia.

A regra foi mantida em sua íntegra até maio de 2003, quando o Decreto no 4.688 passou a prever a elaboração de lista quíntupla composta a partir de seleção interna entre os servidores da autarquia, ampliando, assim, a liberdade de escolha do dirigente máximo do ministério. A norma encontra-se em vigor na forma do art. 5을 do Anexo I do Decreto no 5.257 de 27 de outubro de 2004.

No caso do Departamento de Polícia Rodoviária Federal, vinculado ao Ministério da Justiça, a Lei no 9.654, de 2 de junho de 1998, prevê, em seu artigo 8o, que

os cargos em comissão e as funções de confiança do Departamento de Polícia Rodoviária Federal serão preenchidos, preferencialmente, por servidores integrantes da carreira que tenham comportamento exemplar e que estejam posicionados nas classes finais, ressalvados os casos de interesse da administração, conforme normas a serem estabelecidas pelo Ministro de Estado da Justiça.

Por fim, a Lei $\mathrm{n}^{\mathrm{o}} 11.457$, de 16 de março de 2007, que dispõe sobre a administração tributária federal, prevê, em seu artigo 14, que serão privativos de 
servidores ocupantes de cargos efetivos da Secretaria da Receita Federal do Brasil os cargos em comissão existentes na sua estrutura. Com tal medida, ficará vedada a investidura, em tais cargos, de pessoas que não detenham vínculo efetivo com a própria administração tributária, impedindo-se, assim, que os que não sejam servidores de carreira do próprio órgão venham a exercer cargos de direção ou assessoramento ${ }^{4}$. E, como manifestação de maior comprometimento com a profissionalização da burocracia, foram enviados ao Congresso, em 2008, dois projetos de lei destinados a substituir cargos em comissão de livre provimento por funções comissionadas, privativas de servidores de carreira: o Projeto de Lei no 3.428 , de 2008, que dispõe sobre a criação das Funções Comissionadas do Poder Executivo (FCPE), substituindo 2.477 cargos de confiança pelo mesmo número de funções; e o Projeto de Lei no 3.675, de 2008, que cria funções de confiança denominadas Funções Comissionadas do DNPM (FCDNPM), de exercício privativo de servidores ativos em exercício no Departamento Nacional de Produção Mineral (DNPM). Em ambos os casos, prevê-se a implantação de programas de profissionalização dos servidores a serem designados para tais funções.

É necessário, também, ressaltar o esforço realizado por parte do Judiciário a esse respeito. Recentemente, o Conselho Nacional de Justiça - ao qual se atribuiu a competência de zelar pelo cumprimento do art. 37 da Constituição no âmbito do Judiciário, nos termos da Emenda Constitucional $\mathrm{n}^{-}$45, de 2004 -, no intuito de vetar o emprego de pessoas com qualquer relação familiar com juízes e servidores dirigentes, aprovou, em 18 de outubro de 2005, a Resolução n⿳o 7, que estabelece normas para guiar os tribunais contra o nepotismo ${ }^{5}$. Por fim, o Supremo Tribunal Federal, em agosto de 2008, aprovou súmula vinculante, definindo que é autoaplicável o princípio da moralidade inscrito no art. 37 da Constituição, para os fins de proibir o nepotismo em caráter geral ${ }^{6}$.

No entanto, não existem regras gerais a serem observadas, o que leva ao casuísmo e ao experimentalismo precários ou, por outra via, ao corporativismo, pois apenas

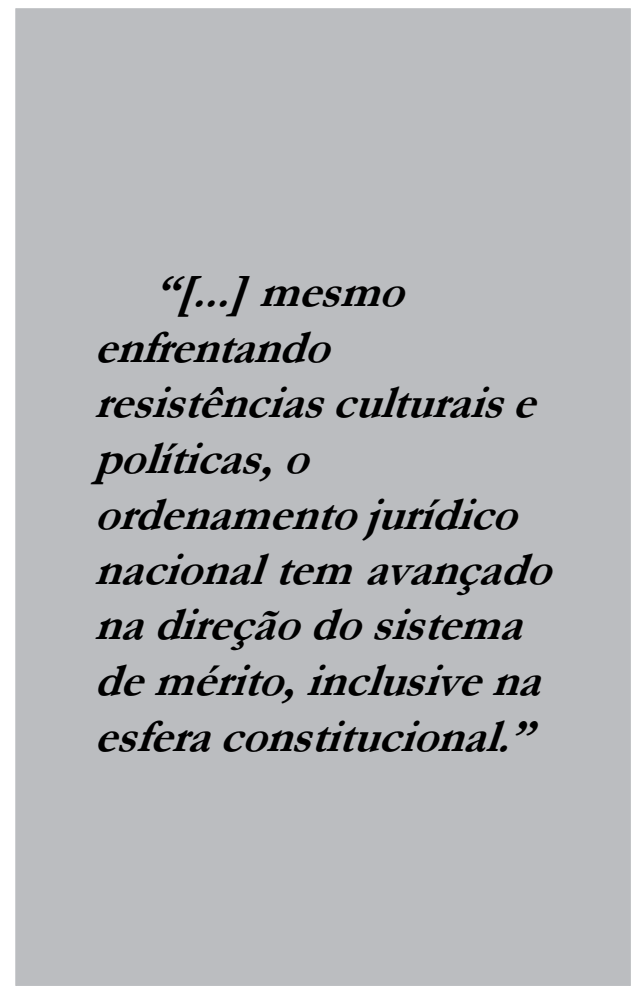

em setores mais organizados e estruturados, com corporações burocráticas fortes, se estabelecem-se e se mantêm regras limitadoras do livre provimento. A melhor alternativa, assim, seria a construção de um sistema misto, balanceado, no qual cargos de direção e de assessoramento possam, em determinados casos, ser exercidos por cidadãos escolhidos pelos agentes políticos legitimados pela eleição e com missões de 
comando e direção do Estado, vinculadas à implementação do programa de governo. Por outro lado, como regra geral, onde tal vinculação política não se faz imprescindível, os cargos de direção e de assessoramento devem ser providos por servidores públicos profissionais, dedicados à carreira pública, selecionados para tais funções pelo mérito individual e devidamente capacitados para essas tarefas. Uma alternativa para essa finalidade tem sido, em diversos países, a criação de um Serviço Civil Superior, ou carreiras de executivos públicos, como o Senior Executive Service nos EUA e que, no Brasil, é exemplificada pela Carreira de Especialistas em Políticas Públicas e Gestão Governamental, no governo federal ${ }^{7}$.

Trata-se de um tema que requer estudos mais aprofundados, que fogem ao objetivo deste trabalho. Relevante, por ora, é constatar a possibilidade de que, no Brasil, carreiras de executivos públicos possam vir a ocupar espaço importante no processo de formulação de políticas públicas a partir da posse de cargos em comissão, ou mediante o exercício de suas atribuições específicas. Avaliações positivas nesse sentido têm sido apresentadas por parte de instituições como o Banco Mundial, para o qual carreiras como os Gestores Governamentais, além de permitir a disseminação de capacidade técnica, poderiam contornar os efeitos do corporativismo e da fragmentação institucional, e ajudar a reduzir o déficit de capacidade institucional entre setores (WORLD B $\mathrm{ANK}$, 2003, p. 648).

No tocante aos cargos comissionados, o Banco Mundial recomenda, fortemente, que seja institucionalizado processo de apuração de qualificações para o seu exercício, bem como ampliada a transparência nos processos de seleção. A fixação de padrões de desempenho para cargos em comissão deve ser implantada independentemente do critério de confiança para a escolha ou retenção de seus ocupantes.

Uma medida importante, destinada a fazer frente ao problema do excessivo provimento de cargos por critérios discricionários, foi a edição, em 21 de julho de 2005, do Decreto no 5.497, que “dispõe sobre o provimento de cargos em comissão do Grupo Direção e Assessoramento Superiores (DAS), níveis 1 a 4, por servidores de carreira, no âmbito da administração pública federal". Trata-se de normativo editado pelo presidente da República que visa, no Poder Executivo, disciplinar o provimento dos cerca de 21.200 cargos em comissão, reduzindo as hipóteses de livre provimento a 6.472 cargos, ou seja, 30\% do total. A nova regra obriga a que pelo menos $75 \%$ dos cargos de níveis 1 a 3 e $50 \%$ dos cargos de nível 4 sejam providos exclusivamente por servidores de carreira, civis ou militares, ocupantes de cargos ou empregos públicos, ou que se tenham aposentado nessa condição.

Embora ainda não haja elementos suficientes para um juízo definitivo sobre a eficácia da medida, cuja implementação ocorre gradualmente à medida que os cargos são providos, ela é fundamental para limitar o livre provimento e incentivar a profissionalização do serviço público. Para tanto, foi associada à obrigação de órgãos, autarquias e fundações da administração pública federal a inclusão de ações voltadas à habilitação de seus servidores para o exercício de cargos de direção e assessoramento superiores em seus planos de capacitação, cabendo à Fundação Escola Nacional de Administração Pública (ENAP) promover, elaborar e executar programas de capacitação e coordenar e 
supervisionar programas de capacitação gerencial executados pelas demais escolas de governo da administração pública federal.

Trata-se de medida que atinge um universo de cerca de 20 mil cargos do Grupo Direção e Assessoramento Superiores, os quais integram um total de 46 mil cargos em comissão ou funções de confiança que podem ser providos discricionariamente na administração direta, autárquica e fundacional (excluídas as instituições federais de ensino), conforme a Tabela $2^{8}$.

Desse total de cargos, separados os que podem ser livremente providos, considerando-se os diferentes níveis no
Grupo DAS, teríamos a seguinte distribuição em setembro de 2007 (Tabela 3).

Do total de quase 22 mil cargos do Grupo DAS, ao qual se aplicam as normas estabelecidas em 2005, nada menos do que 7.251 poderiam, a qualquer tempo, ser livremente providos por servidores não integrantes da administração pública, sem contar o fato de que, entre os demais 14.785 reservados a servidores de carreira, muitos podem ser ocupados, na forma do decreto, por servidores aposentados ou requisitados de outras esferas de governo e de empresas estatais, ou seja, não integrantes dos quadros efetivos da administração federal.

Tabela 2: Cargos em comissão e funções de confiança no governo federal por tipo de provimento -2007

\begin{tabular}{lcc}
\hline Cargo ou Função & $\begin{array}{c}\text { Quantitativo } \\
\text { (providos) }\end{array}$ & $\begin{array}{c}\text { Tipo de } \\
\text { provimento }\end{array}$ \\
\hline CA - Cargo Comissionado de Assessoria & 295 & Livre \\
CAS - Cargo Comissionado de Assistência & 211 & Livre \\
CCD - Cargo Comissionado de Direção & 43 & Livre \\
CCT - Cargo Comissionado Técnico & 1.022 & Privativo \\
CGE - Cargo Comissionado de Gerência Executiva & 651 & Livre \\
DAS - Direção e Assessoramento Superior & 19.995 & Livre ou privativo \\
FCI - Função Comissionada & 1.281 & Privativo \\
FCT - Função Comissionada Técnica & 5.299 & Privativo \\
FGR - Função Gratificada - Lei no $8.216 / 91$ & 17.267 & Privativo \\
FCPAN - Função Comis. dos Jogos Pan-americanos - Mj ${ }^{2}$ & 30 & Privativo \\
NES - Cargo de Natureza Especial & 51 & Livre \\
\hline Total & 46.145 & \\
\hline
\end{tabular}

Fonte: MPOG/SRH. Boletim Estatístico de Pessoal no 137, set. 2007. Elaboração: Autor. 
Tabela 3: Cargos em comissão do Grupo DAS no governo federal conforme possibilidades de provimento -2007

\begin{tabular}{|c|c|c|c|c|c|}
\hline \multicolumn{4}{|c|}{ Cargos existentes } & \multicolumn{2}{|c|}{ Ocupação dos cargos } \\
\hline \multirow{2}{*}{\multicolumn{2}{|c|}{ Cargo }} & \multicolumn{2}{|c|}{ Total } & \multirow{2}{*}{ Privativos } & \multirow{2}{*}{ Não privativos } \\
\hline & & $\mathrm{N}$ & $\%$ & & \\
\hline $\mathrm{CNE}$ & & 51 & 0,23 & 0 & 51 \\
\hline DAS & 6 & 205 & 0,93 & 0 & 205 \\
\hline DAS & 5 & 988 & 4,49 & 0 & 988 \\
\hline DAS & 4 & 3.236 & 14,72 & 1.618 & 1.618 \\
\hline Subto & otal A & 4.429 & 20,15 & 1.618 & 2.862 \\
\hline DAS & 3 & 4.201 & 19,11 & 3.151 & 1.050 \\
\hline DAS & 2 & 6.127 & 27,87 & 4.595 & 1.532 \\
\hline DAS & 1 & 7.228 & 32,88 & 5.421 & 1.807 \\
\hline Subto & otal B & $\mathbf{1 7 . 5 5 6}$ & 79,85 & 13.167 & 4.389 \\
\hline Total & $(\mathbf{A}+\mathbf{b})$ & 21.985 & & 14.785 & 7.251 \\
\hline
\end{tabular}

Fonte: MPOG/SRH. Boletim Estatístico de Pessoal no 137, set. 2007. Elaboração: Autor.

Os dados relativos a DAS 5 e 6 correspondem aos dados disponíveis em junho de 2005 .

A análise da evolução do perfil de ocupação dos cargos em comissão, desde 1999, quando a série passou a ser apurada pela Secretaria de Recursos Humanos do Ministério do Planejamento, Orçamento e Gestão, até 2007, tomando-se como base os dados relativos a junho de cada ano, mostra que houve, até 2004, alguns episódios relevantes.

Entre 1999 e 2004, registrou-se uma redução do percentual de participação de servidores efetivos e requisitados nos cargos em comissão. O declínio foi de 5\% nos cargos DAS 1, o mais baixo na hierarquia, e $4 \%$ nos DAS 4 , chegando a 21, $5 \%$ nos escalões mais altos - DAS 5 e 6. Entretanto, percebeu-se o aumento, em todos os níveis, da participação de servidores aposentados e requisitados de outras esferas no preenchimento dos cargos.

A partir de 2005, esse quadro sofreu ligeira modificação, favorável ao provimento por servidores de carreira do Poder Executivo. Com a vigência do Decreto $\mathrm{n}^{\mathrm{o}}$ 5.497, de 21 de julho de 2005, começa a ocorrer um provimento mais intenso dos cargos em comissão por servidores de carreira, como demonstram os dados da Tabela 4.

Sob uma perspectiva mais abrangente - que é a adotada pelo Decreto no 5.497 , de 2005 -, os dados indicam o restabelecimento do coeficiente existente em 1999 para os DAS 1, aumentando em 9\% e 12\%, respectivamente, o provimento dos DAS 2 e 3 por servidores de carreira do Poder Executivo e em $10 \%$ o dos DAS 4.

A partir de sua edição, os percentuais de provimento por servidores efetivos, segundo o conceito adotado, apresentaram elevação, inclusive nos níveis de cargos em que não há incidência do Decreto. Apenas os DAS 5 continuaram em patamar inferior (4\%) ao verificado em 1999, e os DAS 6 praticamente voltaram ao mesmo patamar de 1999.

Apesar dos avanços, os números deveriam ser mais favoráveis à tese de um 
Tabela 4: Ocupação de cargos em comissão DAS por servidores “efetivos" segundo critério do Decreto no 5.497/2005 - Poder Executivo, Brasil, 1999-2007

\begin{tabular}{c|c|c|c|c|c|c|c|c|c|c|c}
\hline Cargo & $\mathbf{1 9 9 9}$ & $\mathbf{2 0 0 0}$ & $\mathbf{2 0 0 1}$ & $\mathbf{2 0 0 2}$ & $\mathbf{2 0 0 3}$ & $\mathbf{2 0 0 4}$ & $\mathbf{2 0 0 5}$ & $\mathbf{2 0 0 6}$ & $\mathbf{2 0 0 7}$ & $\begin{array}{c}\text { Média } \\
\text { total }\end{array}$ & $\begin{array}{c}\text { Média } \\
\mathbf{2 0 0 5} / \mathbf{2 0 0 7}\end{array}$ \\
\hline DAS 1 & 82,60 & 83,70 & 82,30 & 79,50 & 79,10 & 74,00 & 72,30 & 75,30 & 75,60 & 78,27 & 74,40 \\
DAS 2 & 81,80 & 81,40 & 79,00 & 77,60 & 79,80 & 76,90 & 74,70 & 76,60 & 77,60 & 78,38 & 76,30 \\
DAS 3 & 83,20 & 83,90 & 83,40 & 82,10 & 80,00 & 77,20 & 76,40 & 78,20 & 79,80 & 80,47 & 78,13 \\
DAS 4 & 72,30 & 70,50 & 68,70 & 69,80 & 65,30 & 64,50 & 64,20 & 66,70 & 68,20 & 67,80 & 66,37 \\
DAS 5 & 71,20 & 65,60 & 69,10 & 66,60 & 60,90 & 58,70 & 59,40 & 62,80 & 63,30 & 64,18 & 61,83 \\
DAS 6 & 58,20 & 58,90 & 58,20 & 62,20 & 50,30 & 48,60 & 55,20 & 55,50 & 57,10 & 56,02 & 55,93 \\
\hline
\end{tabular}

Fonte: Ministério do Planejamento, Orçamento e Gestão/Boletim Estatístico de Pessoal 1999/2007.

Elaboração: Autor. Consideradas posições em maio de cada ano sobre total de cargos ocupados.

provimento "profissionalizado" dos cargos em comissão. Considerado o ano de 1999 como ponto de partida para efeitos de comparação, constata-se redução do provimento dos cargos em comissão por servidores efetivos nesse período. Embora os dados para o conjunto da administração demonstrem que os quantitativos de cargos que devem ser providos por servidores efetivos, conforme a conceituação adotada pelo Decreto $\mathrm{n}^{\mathrm{o}} 5.497 / 2005$, exibiram melhoria no quadro geral, há importantes indicativos das dificuldades em promover a profissionalização dos cargos em comissão mediante o seu provimento por servidores de carreira em algumas áreas da administração. O Decreto ainda não foi suficiente para restabelecer os patamares existentes em 1999. Dados relativos a períodos mais recentes (2003-2007) mostram que a tendência de ocupação desses cargos por pessoas sem vínculo com a administração pública, considerado o total de cargos existentes, tem-se mantido estável. Levantamento promovido em 2007 pelo Ministério do Planejamento, Orçamento e Gestão apontava para os seguintes dados de ocupação dos cargos, considerados apenas aqueles sujeitos ao referido Decreto (Tabela 5).

Tabela 5: Cargos DAS 1 a 4 (vagos e ocupados) - Poder Executivo - tipo de provimento - setembro de 2007

\begin{tabular}{l|c|c|c}
\hline Cargo & $\begin{array}{l}\text { Servidores } \\
\text { com vínculo }\end{array}$ & $\begin{array}{l}\text { Servidores } \\
\text { sem vínculo }\end{array}$ & Cargos vagos \\
\hline DAS 1 & 71,53 & 23,06 & 5,40 \\
DAS 2 & 71,11 & 19,59 & 9,31 \\
DAS 3 & 69,76 & 17,87 & 12,37 \\
DAS 4 & 62,22 & 28,49 & 9,29 \\
\hline Total & 69,60 & 21,30 & 8,57 \\
\hline
\end{tabular}

Fonte: Ministério do Planejamento, Orçamento e Gestão. Nota Técnica Conjunta SRH/SEGES $\mathrm{n}^{\mathrm{o}} 01 / 2007$. 
Estatisticamente, mais de dois anos após o início da sua vigência, os patamares de profissionalização dos cargos em comissão fixados pelo Decreto $\mathrm{n}^{-} \mathbf{0} .497$ não se achavam ainda atendidos, embora, segundo o Ministério do Planejamento, Orçamento e Gestão, os atos de provimento que vêm sendo praticados desde julho de 2005 observem, estritamente, a orientação normativa, o que significa dizer que não pode haver provimento desses cargos por servidores que não atendam aos critérios estabelecidos.

Quanto à possibilidade de que os percentuais venham a ser atendidos em curto ou médio prazo, as situações existentes em diferentes órgãos são indicativo claro das dificuldades enfrentadas na administração pública federal. Os dados apurados pelo Ministério do
Planejamento, Orçamento e Gestão indicam algumas situações críticas, exemplificadas pela relação constante do Gráfico 2, que aponta os órgãos em que o percentual total de cargos ocupados por pessoas sem vínculo efetivo é superior a $40 \%$ do total de cargos existentes nos níveis 1 a 4 .

Como se percebe, em geral, são órgãos que não dispõem de quadros de pessoal estruturados, em função de políticas de não reposição de quadros adotadas a partir do início dos anos 1990, ou por se tratarem de órgãos de criação ainda recente, como os ministérios do Desenvolvimento Agrário e do Desenvolvimento Social, o Ministério do Esporte e o Ministério do Turismo. Trata-se de casos em que, em função dos processos de privatização, notadamente no setor de infraestrutura, particularmente o

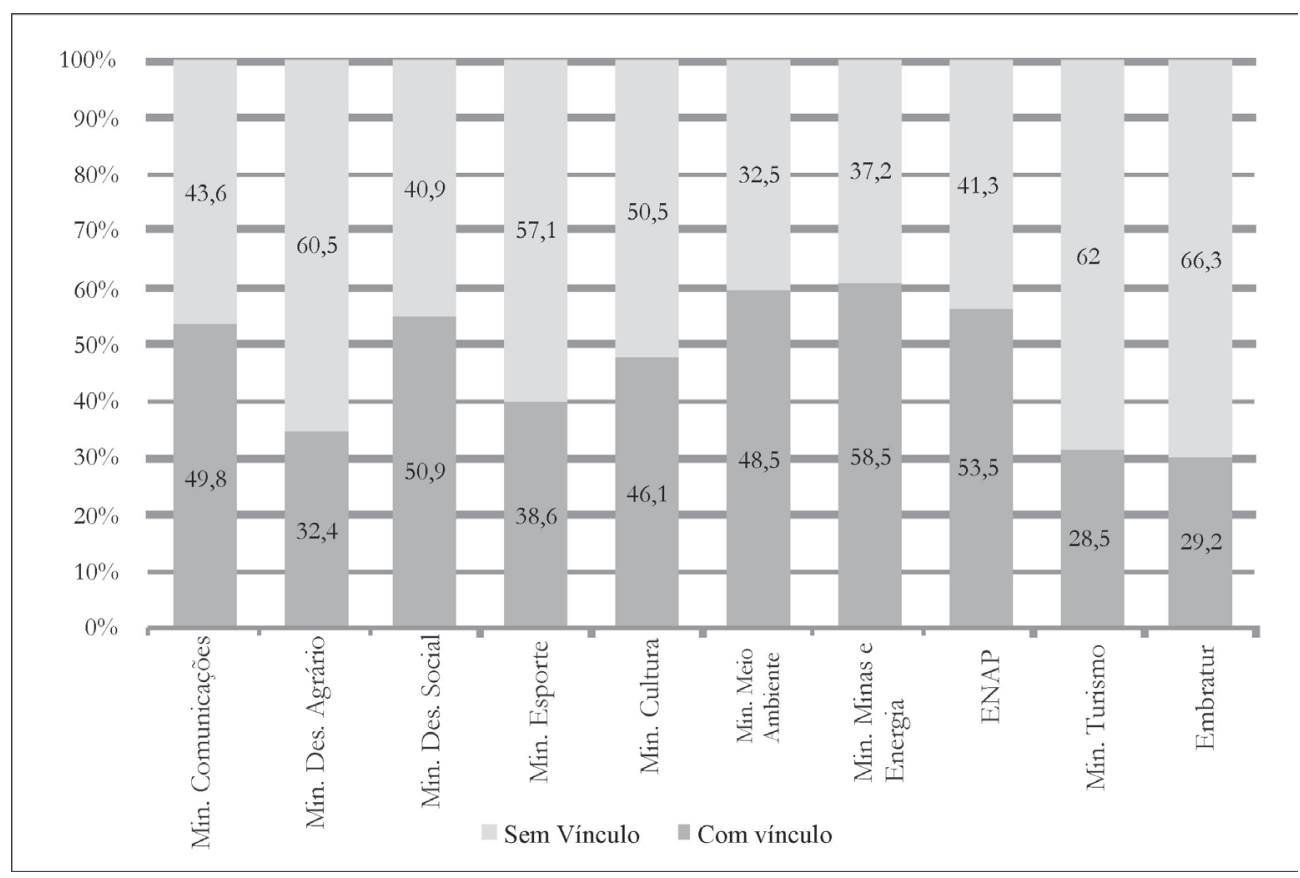

Fonte: Ministério do Planejamento, Orçamento e Gestão. Nota Técnica Conjunta SRH/SEGES no 01/2007.

Gráfico 2: Órgãos e entidades com \% de comissionados efetivos inferior a $60 \%$ do total (DAS 1 a 4) - Brasil, setembro de 2007 
Ministério das Comunicações, o Ministério das Minas e Energia e o Ministério dos Transportes, deixaram de contar com a requisição de empregados de empresas estatais, hoje privatizadas - recurso até então largamente empregado. Considerando-se os órgãos com estruturas mais profissionalizadas, ou seja, com percentuais de provimento de cargos comissionados por servidores de carreira superiores a $85 \%$ do total aprovado, verifica-se a ocorrência de algumas situações bastante óbvias, como demonstra o Gráfico 3.

Constata-se, em especial, serem órgãos em que a estrutura de cargos efetivos é composta por carreiras estruturadas - caso do Ministério da Ciência e Tecnologia, CNEN, CNPQ, INPI e Fiocruz, tidos como órgãos de excelência em suas áreas. Em outras situações, como no INSS, existe uma estrutura cuja origem remonta há décadas e que adotou, ao longo dos últimos anos, medidas no sentido de reduzir drasticamente os cargos em comissão de livre provimento, dotandose de funções de confiança privativas de servidores; enquanto os cargos de livre provimento mantidos, face ao perfil e especialização requeridos, são exercidos, em grande medida, por servidores efetivos da autarquia. Finalmente, registram-se duas situações emblemáticas no que se refere à constituição de "ilhas de excelência”, segundo o padrão burocrático: o Ministério da Fazenda e o Ministério das Relações Exteriores. Em ambos os casos, são órgãos com amplo histórico de medidas destinadas a promover sua profissionalização, mediante a criação de carreiras específicas, regidas em graus diferenciados pelo sistema do mérito, mas que, ao longo das últimas quatro décadas,

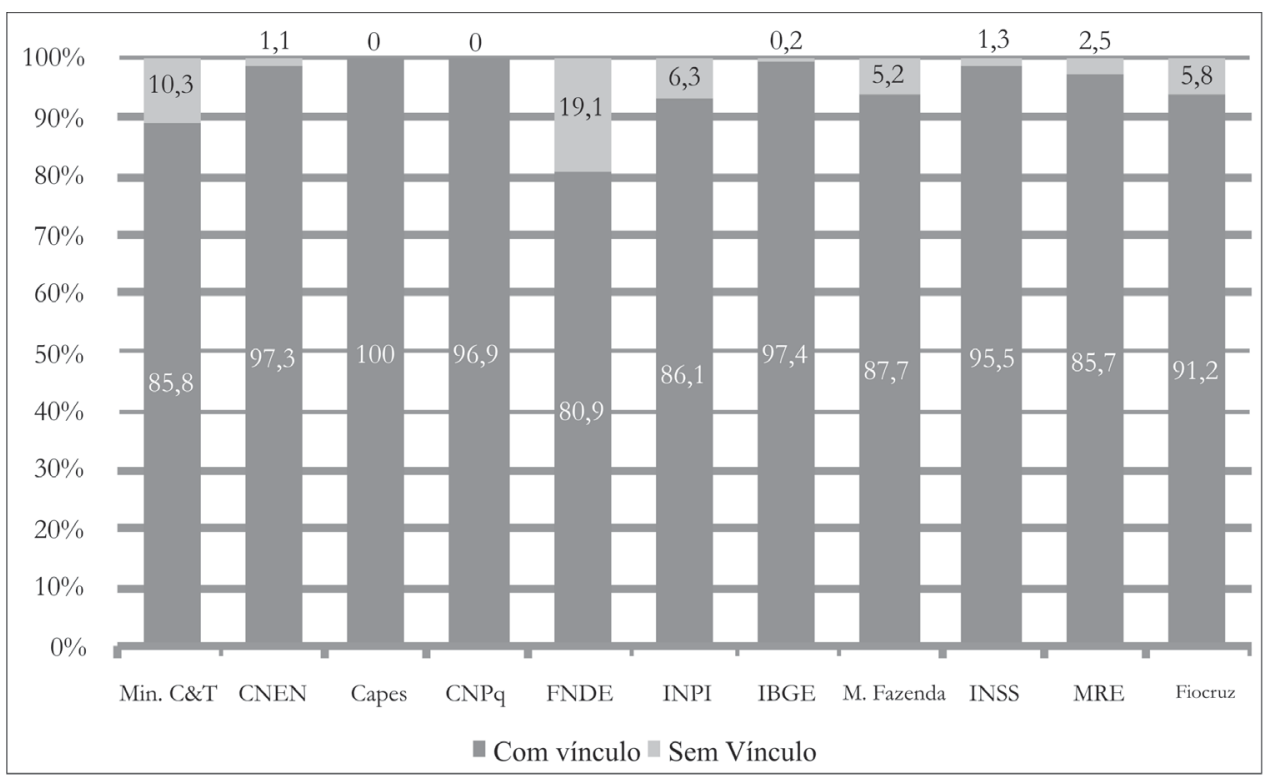

Gráfico 3: Órgãos e entidades com \% de comissionados efetivos superior a $85 \%$ do total (DAS 1 a 4) - Brasil, setembro de 2007 
transformaram-se em reservas de valor para o conjunto da administração pública, como a diplomacia, cujo qualificado quadro ofereceu ao país diversos ministros de Estado.

No entanto, trata-se, ainda, de casos excepcionais, sendo a regra as situações intermediárias, em que a exiguidade de quadros de carreira, ou seu perfil de qualificação, não permite que a administração possa recorrer ao provimento interna corporis como forma de assegurar o dinamismo, a qualidade da gestão e o grau de resposta necessário. Há também a convivência com as pressões oriundas do clientelismo e do patrimonialismo para o provimento de cargos que são, por definição, de livre nomeação, quando não o aparelhamento político das estruturas de comissionamento, sob o argumento de que é a confiança ou a afinidade política o fator decisivo para a escolha do titular. Nessa situação, encontram-se órgãos como: Ministério do Trabalho e Emprego; Ministério dos Transportes; Ministério da Educação; Inep; CVM; Susep; Ministério da Justiça; Ministério da Saúde; DNIT; e outros em que ainda não há estruturas suficientemente profissionalizadas e protegidas das nomeações políticas.

Além da burla à exigência de concurso público, essas hipóteses ainda bastante amplas de uso dos cargos públicos permitem o favorecimento de correligionários políticos, evidenciando resquícios de patrimonialismo na administração pública federal, possivelmente um dos maiores entraves à implementação de políticas destinadas à efetiva profissionalização do serviço público. A utilização desses expedientes de caráter pragmático afasta o interesse na busca de soluções para os problemas que afligem o quadro permanente, objeto da organização de carreiras, em um mecanismo disfuncional de segundo grau de difícil solução. Manobras que, derivadas do corporativismo ou do patrimonialismo, permitem que o serviço público, no Brasil, continue a ser o esteio dos compadres, dos amigos, dos protegidos.

\section{Conclusão}

A partir dos dados apurados e examinados neste estudo, pode-se afirmar que, em relação à política e estrutura de cargos comissionados e funções de confiança, historicamente (e o atual momento é uma exemplificação desta nota estrutural), a administração pública brasileira tem avançado de maneira muito lenta no sentido de sua ocupação de forma profissionalizada.

Quanto aos cargos executivos ou de assessoramento que devam ser providos por servidores, é de se considerar que não basta a satisfação dessa condição genérica, ou mesmo pertencer a determinada carreira, para que o exercício do cargo comissionado esteja legitimado. Para que não se produza um spoils system com reserva de mercado, é necessário que o acesso seja atrelado a processos de qualificação para o exercício da gerência e do assessoramento, guardando correspondência com a posição do servidor na carreira. Além disso, a existência de carreiras às quais estejam vinculadas linhas de acesso a cargos de direção e assessoramento pode ter grande importância para assegurar a organicidade e a continuidade das políticas públicas.

No entanto, o excessivo insulamento poderia dar origem à exacerbação do esprit de corps e à maior dificuldade na implementação de mecanismos de prestação de contas e de controle social, contrapondo-se o incentivo à carreira à necessidade de 
permeabilização das instituições ao fluxo de novas ideias e práticas.

A profissionalização é pressuposto para que as organizações públicas possam ingressar em patamar diferenciado, tornando-se menos sensíveis às interferências fisiológicas ou clientelistas que, em regra, impedem que as organizações possam ser geridas de forma mais racional, tendo como horizonte o interesse público e a continuidade de suas políticas. Do maior ou menor grau de interferência da política de clientela na gestão decorre, em grande medida, a eficiência e a efetividade das organizações públicas. Ademais, o elevado grau de dependência dos ocupantes desses cargos a apoios políticos, partidários ou de grupos de interesse para a permanência nos cargos tende a colocar em xeque a capacidade de julgamento, produzindo, em lugar da necessária responsividade ao sistema político, inerente à democracia representativa, uma situação de captura ou dependência que fragiliza o processo decisório governamental e propicia a ocorrência de práticas corruptas.

Tal burocracia patrimonialista, longe de ser profissionalizada e minimamente capacitada para atender aos anseios da sociedade e servir aos cidadãos, torna-se presa fácil de um sistema predatório, que dilapida o patrimônio do Estado para atender aos desejos de agentes privados, muitas vezes pouco ou quase nada comprometidos com os objetivos da coletividade. Ainda que a ocupação de cargos públicos por cidadãos que não integram os quadros da administração pública não seja, obrigatoriamente, indicativo de má conduta ou de ineficiência, e que os perfis de seus ocupantes, em termos de formação acadêmica e experiências políticas, profissionais, associativas ou administrativas anteriores?, permitam concluir pela capacidade de serem formuladores de políticas ou executivos públicos competentes, o elevado número desses cargos e a inexistência de critérios para seu provimento submetem o interesse público a um grau de discricionariedade ou subjetividade muito superior ao que se faz presente em democracias avançadas, e mesmo em um país no qual a concepção

"No tocante aos cargos comissionados, o Banco Mundial recomenda, fortemente, que seja institucionalizado processo de apuração de qualificações para $o$ seu exercício, bem como ampliada a transparência nos processos de seleção."

de burocracia foi sempre permeada pela aversão à criação de uma casta. No atual quadro, o Brasil ainda está distante de poder considerar que sua burocracia exerce, efetivamente, papel similar ao daqueles países no processo decisório governamental e na gestão das políticas públicas.

A correção de tal disfunção não é, em si, a única possibilidade para extirpar a corrupção e assegurar uma gestão 
democrática, transparente e responsiva ao conjunto da sociedade, mas, sem dúvida, tornaria mais difícil a ocorrência de tantos desvios quanto os que temos presenciado ao longo dos anos, contribuindo para a obtenção de níveis de accountability e eficiência mais adequados aos interesses da sociedade.

(Artigo recebido em janeiro de 2009. Versão final em fevereiro de 2009)

\section{Notas}

${ }^{1}$ Segundo Maranto (2001), os political apppointees são mais receptivos a contatos com o Congresso: em survey realizado em 1999, constatou-se que $52 \%$ deles mantinham contatos com congressistas e seus assessores, enquanto somente $19 \%$ dos executivos de carreira reportavam o mesmo tipo de relacionamento.

${ }^{2}$ Acima do DAS 4 e abaixo do Ministro de Estado, existem apenas três níveis hierárquicos: DAS 5 e 6 e os Cargos de Natureza Especial, tais como Secretário Executivo de ministérios.

${ }^{3}$ Sobre os usos e práticas de gestão predatória envolvendo os cargos em comissão no Brasil, ver Santos e Cardoso, 2005.

${ }^{4}$ Esse seria um importante precedente, após diversas tentativas de profissionalização da gestão de órgãos públicos. Houve, ainda no ano de 2004, duas tentativas no mesmo sentido, no Departamento Nacional de Produção Mineral (DNPM) e no Departamento Nacional de Infraestrutura em Transportes (DNIT); mas, em ambos os casos, os dispositivos foram rejeitados pelo Congresso.

${ }^{5}$ No âmbito das empresas estatais, há também regras restritivas: no BNDES, historicamente uma instituição meritocrática, que resistiu às tendências clientelísticas ao longo dos anos 1940 e 1950, os cargos de direção inferiores aos de Diretoria são privativos de servidores de carreira; no Banco do Brasil, há regras de mesma natureza.

${ }^{6} \mathrm{O}$ conteúdo da súmula vinculante é o seguinte: “A nomeação de cônjuge, companheiro ou parente em linha reta colateral ou por afinidade até o terceiro grau, inclusive, da autoridade nomeante ou de servidor da mesma pessoa jurídica investido em cargo de direção, chefia ou assessoramento para o exercício de cargo em comissão ou de confiança ou ainda de função gratificada na administração pública direta ou indireta em quaisquer dos poderes da União, dos estados, do Distrito Federal e dos municípios, compreendido o ajuste mediante designações recíprocas, viola a Constituição Federal".

${ }^{7}$ No Brasil, essa solução tem como exemplo a criação da Carreira de Gestores Governamentais, pela Lei no 7.834 , de 1989, com atribuições de exercer atividades de formulação, implementação e avaliação de políticas públicas e de direção e assessoramento nos escalões superiores da administração federal. Trata-se de servidores recrutados por concurso público de âmbito nacional, e sujeitos a curso de formação ministrado pela Escola Nacional de Administração Pública (ENAP) com duração de seis meses. Até julho de 2007, achavam-se providos cerca de 800 cargos dessa carreira, cujos ocupantes, em face do caráter generalista da carreira, têm formações acadêmicas bastante diversificadas, e um número expressivo detém dupla formação superior ou formação em nível de pós-graduação. $O$ perfil das atribuições da carreira é, efetivamente, muito próximo do verificado no Senior Executive Service dos Estados Unidos da América, quadro de executivos públicos de carreira criado em 1978, composto por cerca de 6.800 membros ativos que exercem funções estratégicas de gerenciamento de programas e agências governamentais. 
${ }^{8}$ Todavia, os dados referem-se apenas aos cargos e funções providos em momento determinado (agosto de 2007). Considerados os cargos e funções existentes, somente no caso dos cargos do Grupo DAS, devem ser somados, pelo menos, mais 1.770 cargos vagos existentes na mesma data.

${ }^{9}$ Ver, quanto a esse aspecto, o estudo coordenado por D’Araújo (2007).

\section{Referências bibliográficas}

BALLENSTEDT, Brittanny. Panelists suggest reducing reliance on political appointees. Government Executive, 25 Oct 2007, disponível em http://govexe.com/dailyfed/1007/102507b1 htm.

BAQUero, Marcello. Eleições e capital social: uma análise das eleições presidenciais no Brasil (2002-2006). Opinião Pública, Campinas, vol. 13, no 2, Novembro, 2007, p. 231-259.

D’Araújo, Celina Maria. (coord.). Governo Lula, contornos sociais e políticos da elite no poder. 1.ed. Rio de Janeiro: CPDOC/FGV, 2007.

Golden, Marissa Martino. What Motivates Bureaucrats? Politics and Adminitration During the Reagan Years. New York: Columbia University Press, 2000, 238 p.

Krause, George A., Lewis, David E. \& Douglas, James W. Political Appointments, Civil Service Systems, and Bureaucratic Competence: Organizational Balancing and Executive Branch Revenue Forecasts in the American States. American Journal of Political Science, Vol. 50, no 3, July 2006, p. 770-787.

LEwis, David E. Presidents and the politicization of the United States Federal Government, 1988-2004. Paper presented at the 2005 Annual Meeting of the American Political Science Association, Washington, DC. Disponível em setembro de 2007 em http:/ /www.dartmouth.edu/ govt/docs/Lewis.pdf.

Testing Pendleton's Premise: Do Political Appointees Make Worse

Bureaucrats? The Journal of Politics, Vol. 69, no 4, November 2007, p. 1073-1088.

Maranto, Robert. Why the President Should Ignore Calls to Reduce the Number of Political Appointees. 27 February 2001, disponível em http://www.heritage.org/Research/ GovernmentReform/BG1413.cfm.

Ministério do Planejamento, Orçamento e Gestão. Secretaria de Recursos Humanos. Boletim Estatístico de Pessoal no 137, set. 2007.

Rourke, Francis E. Bureaucracy, Politics and Public Policy. Litle, Brown and Company: Boston, 1976, 2nd Edition, 208 p.

SANTOS, Luiz Alberto \& CARDOSO, Regina Luna Santos. Corrupção, nepotismo e gestão predatória: um estudo do caso brasileiro e alternativas para seu enfrentamento. XVIII Concurso del CLAD sobre Reforma del Estado y Modernización de la Administración Pública, Santiago-Chile, 2005. Disponível em maio de 2007 em http:/ /www.clad.org.ve/ fulltext/ 0052003.pdf.

United States House of Representatives. Committee on Government Reform U.S. House of Representatives. Policy and Supporting Positions. November 2004. 
United States House of Representatives. Committee on Government Reform Minority Staff Special Investigations Division. The Growth of Political Appointees in the Bush Administration. May, 2006. Disponível em novembro de $2007 \mathrm{em}$ http:/ / oversight.house.gov/documents/20060503160909-97328.pdf.

WorLD BANK. Brazil: equitable, competitive, sustainable - Contributions for Debate. Washington: The World Bank, 2003, 655 p. 


\section{Resumo - Resumen - Abstract}

\section{Burocracia profissional e a livre nomeação para cargos de confiança no Brasil e nos EUA}

Luiz Alberto dos Santos

A problemática do emprego de cargos de livre nomeação e exoneração para assegurar o comando político e administrativo na máquina pública tem sido objeto, tanto no Brasil quanto nos Estados Unidos, de diversos questionamentos. Este artigo debate a situação em ambos os países, com base em alguns dados esclarecedores obtidos pela comparação entre as estruturas de cargos comissionados e suas quantidades e formas de provimento existentes, no nível do governo federal, relativos à quantidade, tipos e emprego dos cargos em comissão, destacando-se a diferenciação no que se refere ao uso desses cargos, assim como promove, a partir da literatura da área, um exame da influência da utilização dos cargos de livre provimento sob o aspecto do conflito entre "competência neutra" e "competência responsiva". A partir dos avanços alcançados desde 1998 no Brasil, conclui-se pela necessidade do aprofundamento da profissionalização das estruturas de comissionamento, tendo em vista a possibilidade de que uma estrutura menos vulnerável às injunções da política clientelista possa melhor atender aos princípios da eficiência e da transparência.

Palavras-chave: profissionalização, burocracia, governança.

\section{Burocracia profesionaly la libre ocupación para cargos comisionados en Brasily en los EEUU} Luiz Alberto dos Santos

El problema de la utilización de cargos comisionados de libre ocupación para garantirse el comando político y administrativo de la burocracia gubernamental ha sido objeto de críticas y investigaciones en Brasil y en los Estados Unidos de América. Este artículo intenciona debater la situación en los dos países utilizando los datos obtenidos a través de la comparación entre los cuadros de cargos comisionados existentes en las dos estructuras, su número, tipos de empleo y las formas de ocupación en vigor, en nivel nacional. Se destaca la diferente utilización de esos cargos, como también se examina, a partir de una revisión de la bibliografía acerca del tema, la influencia observable de la variegada y extensa utilización de los cargos de libre ocupación, desde la perspectiva del conflicto entre la "competencia neutra" y la "competencia responsiva". A partir de los avances percibidos desde 1998 en Brasil, se concluye por la necesidad de profundizar la profesionalización de las estructuras de "comisionamientos", considerando la posibilidad de construcción de una estructura menos vulnerable a las variables políticas, al clientelismo y populismo, para mejor atender a los principios de la eficiencia, de rendición de cuentas (accountability) y de la transparencia.

Palabras clave: profesionalización, burocracia, gobernanza.

\section{Professional bureaucracy and political appointments for governmental positions in Brazil and in the USA \\ Luiz, Alberto dos Santos}

The intensive use of political appointments for governmental positions to reassure political and administrative rule of governmental bureaucracy in the United States of America and in Brazil has long been studied and criticized. This paper discusses the scenarios in both countries and compares their structures using data obtained by the comparison between their legal framework, their number, nature of employment and possible ways of access in the Federal level. Emphasis relies upon the diverse and differentiated use of these appointments, according to the literature in 
the area, as well as in the examination of its observable influence as long as the conflict of "neutral" and "responsive" competence is concerned. The progress observed in Brazil since 1998 buttress the conclusion that more professionalization in political and bureaucratic nominations is needed, keeping in mind that a professionalized bureaucracy is less vulnerable to the variables that clientelism and populism brings and is better linked to successful observance of the principles of efficiency, accountability and transparency.

Keywords: professionalization, bureaucracy, governance.

Luiz Alberto dos Santos

Bacharel em Direito pela Universidade Federal do RS, e em Comunicação Social pela Pontifícia Universidade Católica do RS e Universidade de Brasília (UnB). Especialista em Políticas Públicas e Gestão Governamental pela ENAP Escola Nacional de Administração Pública. Mestre em Administração e Doutor em Ciências Sociais pela UnB. Subchefe de Análise e Acompanhamento de Políticas Governamentais da Casa Civil da Presidência da República.

Contato: luizsan@planalto.gov.br 